\title{
Jenny Lind, Voice, Celebrity
}

There is one image, at once blank and highly loaded, that ushers in the celebrity soprano Jenny Lind with iconic force: an 1848 daguerreotype by the London photographer William Edward Kilburn (Pl. 1). Lind is captured in a statuesque pose, standing at the side of an upright piano. She is sideways to the camera, but with her face turned about three quarters to the observer. Her left arm is stretched down, slightly forwards, so as to reach the keyboard, where her fingers gently shape an A-minor chord. Her right hand is also set up to evoke musical sounds. It is a pianist's hand, formed into a beautiful, perfectly mastered arc; but instead of pressing the keys, it rests on the instrument's top. Look away from this area into the mirror to the right, and this scene of muted sonic evocations disappears. At the least, it is re-cast in a reverse system of objects and subjects. Now it is the furniture that, so to speak, plays Lind. The glass on the wall reflects her back, her right hand delicately sustained by a nondescript surface. Her black lace shawl stands out starkly on the whiteness of her shoulders, embroidering them into flowering motifs that blend with the carved mirror frame and the ornate side table beneath it. In fact, all of Lind's garments-her shawl, the shining folds of her silky dress, the stripes of her sleeves-assimilate her into the ambience of the room - the flowery carpet, the elaborate furniture, the piano's drapery with its linear pattern. If something cuts in on this proliferation of forms and materials it is the two bare walls surrounding Lind's figure. Why such blankness? What its metaphorical reminder?

\section{[INSERT PL. 1 ABOUT HERE]}

Kilburn's portrait is just one of countless that emerged in London in the wake of midcentury Lind mania. The soprano, widely known as the 'Swedish Nightingale', was commended as much for her vocal skills as for her integrity and religious piety. Lind moved to England, where she swiftly ascended to success in the opera house, in 1847, before embarking on a two-year concert tour of the US at the invitation of the showman and businessman P. T. Barnum in 1850. Recent developments in printmaking and the sheetmusic industry among other factors meant that her celebrity extended, to an unprecedented degree, well beyond the theatre, cutting through all classes of society. The whole London cultural industry was mobilized. Lind mania was produced and disseminated through a variety of media, photographs being merely one component of a rich tapestry of visual and other representations. Contemporaries were prone to seize on the technical mastery underpinning early daguerreotypean attempts as they debated the merits and limitations of the new medium. 'That the reflection in the glass is equally perfect with the original', asserted the juries of the 1851 Great Exhibition-where Kilburn's likeness of Lind was displayed - is the point worthy of remark and commendation'. ' The mirror in Pl. 1 crystallizes the tension between copy and original that prompted critical scrutiny; yet at a deeper level it also serves as a paradigm for photography tout court. The rhetoric of mimesis, even of identity, of object and image rehearsed on the looking-glass runs through early

\footnotetext{
I am grateful to the several voices who have shaped my own: to Harriet Boyd-Bennett, Oskar Cox Jensen, James Davies, David Kennerley, Roger Parker, Ditlev Rindom, Susan Rutherford, Emanuele Senici and an anonymous reader. A special thanks to Gavin Williams, for prodding me into a fascinating subject in the first place. ${ }^{1}$ Reports by the Juries on the Subjects in the Thirty Classes into Which the Exhibition Was Divided (London, 1852), 276.
} 
discussions of the medium, ones that recent studies have shown to be receptive to changing notions of resemblance. Even as it mobilizes claims of 'truthfulness' and 'immediacy' about representation, the reflected image introduces a fragmentation to the self that taps into a broader reconfiguration of subjectivity and the purposes of mimetic arts. As art historian Jan von Brevern has proposed, early photographic reference was far from being understood simply in terms of a transparent reproduction of reality; instead, photography functioned as a 'dissecting' medium, one that undermined the notion of a coherent self by revealing the multiple versions or identities that constitute any individual. ${ }^{2}$

The tension between identity and difference underscored by Kilburn's photograph also dovetails with wide-ranging authenticity discourses that were fostered by Lind's celebrity status. Scholars of celebrity have explained how the invocation of a 'linear', 'unmediated' communication between celebrities and their audiences was-indeed is-one of the key mechanisms on which celebrity status has been based. Questions of 'presence' and 'absence', of the individual's 'true' identity versus its manufactured (technologicallyproduced) double, lay at the core of contemporary debates about Lind. In this article, I want to pursue some of these binaries at the intersection of various media and materials. ${ }^{3}$ I will focus on Lind's voice, and attempt to tease it out through (rather than from) the representational and reproductive economy that constituted her as a celebrity. To press on Kilburn's photograph a little further, a wealth of signs entangle it with contemporary descriptions of Lind's sonorities and personality. The patina of creative agency, even of authorial voice, it casts on the singer; her dignified stance as she poses for the camera; her finely decorated shawl, almost a visual analogue to her famous flair for ornamenting operatic lines: in short, and as we shall see, the picture is loaded with nineteenth-century markers of Lind's vocal and broader musical identity. To interrogate the blank surface of the walls is in this sense to ask whether it too participates in this cross-media imagining of the celebrity soprano.

In what follows, I will thus explore Lind's voice by engaging issues of mediation. Mediated voices have up to now largely been thought about in connection with classic technological turns and apparatuses, in particular with early sound reproduction devicesthe phonograph, the telephone, radio and so on. The ideology of immediacy and authenticity in which voices have been embroiled has been explained by some as inextricably tied up to the new semiotics of sound developed around those late-nineteenthand early-twentieth-century inventions (even though sonic, and particularly vocal, immediacy is more generally a long-standing tenet of modern Western culture). ${ }^{4}$ To discuss mediated voices in ways that eschew directly technological considerations is nevertheless to enter mostly uncharted territory. ${ }^{5}$ My intention here is to gesture towards a more

\footnotetext{
${ }^{2}$ See Jan von Brevern, 'Resemblance After Photography', Representations, 123/1 (2013), 1-22.

${ }^{3}$ I will, from now on, refrain from using scare quotes around such terms as immediacy, unmediated, authentic(ity), real(ity), presence and originary.

${ }^{4}$ Steven Connor summarizes this tenet by saying that 'Hearing has traditionally been seen as the medium of experience, intuition, intensity, and immediacy': Connor, 'Voice, Technology and the Victorian Ear', in Roger Luckhurst and Josephine McDonagh (eds.), Transactions and Encounters: Science and Culture in the Nineteenth Century (Manchester and New York, 2002), 16-29 at 18.

${ }^{5}$ Georgina Born has, of course, theorized mediation as a way of rethinking music's ontology and moving beyond the dualism between 'music' and 'context'; see her 'On Musical Mediation: Ontology, Technology and Creativity', Twentieth-Century Music, 2/1 (2005), 7-36, and 'For a Relational Musicology: Music and Interdisciplinarity, Beyond the Practice Turn', Journal of the Royal Musical Association, 135/2 (2010), 205-43. For an exploration of voice as mediated by metre (understood here as technology) in Victorian poetry, see Yopie Prins, 'Robert Browning, Transported by Meter', in Meredith L. McGill (ed.), The Traffic in Poems: NineteenthCentury Poetry and Transatlantic Exchange (New Brunswick and London, 2008), 205-30.
} 
encompassing understanding of voices as mediated, and to do so by analysing Lind's sounds in and through the wider London context of Lind mania.

Mediation lends itself to addressing questions at the crossroads of voice and celebrity studies: notions of presence, immediacy and authenticity lie at the heart of the discursive apparatus that has long shaped both voices and star images. More than this, such notions have shaped the voice as an image. From identity politics to psychoanalysis and literary theory, 'the voice' has with little variance been conceptualised as an attribute or manifestation of the self. (As James Q. Davies puts it, the traditional liberal assumption is: 'I have a voice, therefore I am'. ${ }^{6}$ Yet the qualities contemporaries said characterized Lind's voice-some sort of mystic purity, sweeping thrust (as well as lightness) and so on-are best understood, I shall suggest, under a broader perceptual regime associated with her celebrity status. In other words, the severance occasioned by a variety of printed and visual materials between voice and name, presence and absence, direct sonic experience and the sensorium elicited by technological reproduction is ultimately key to understanding the perceptual and ideological system surrounding Lind's voice.

\section{Body matters}

It is actually necessary to hear Lind. ${ }^{7}$

Press reports of Lind's death in Malvern, Worcestershire, in 1887 are caught up in a singular tension between subduing and magnifying the legacy of her tremendous mid-century celebrity. They date from forty years after her London debut, as Alice in an Italian translation of Meyerbeer's Robert le diable, which initiated her stardom in England and, soon afterwards (as a concert singer), in the US. ${ }^{8}$ In an attempt to capture a musical career that lasted for almost half a century, their authors broach the passing of time-the flow of history, of generations. The staunchest among the pessimists blame this stream for the withering of a personality that had once attracted countless audiences, and now is mourned only by a close circle of friends. ${ }^{9}$ For others, more positive-minded, this relentless historical movement cannot corrupt-on the contrary, it proves the sturdiness of-Lind's appeal. Even the latter, however, have to tone down their claims in the face of the remoteness, indeed the irrecuperability of their object. A sense of loss obfuscates Lind's continuing renown: 'that bright halo', as the Magazine of Music put it, 'which marks a delight placed just beyond our reach. ${ }^{10}$ Such estrangement follows as much from Lind's death as from a lack of familiarity with a singer who had long since retired from the operatic stage. ${ }^{11}$ Perhaps most notable about this hovering between past and present, then, is the way it comes to bear a persistent dichotomy: between voice and name.

\footnotetext{
${ }^{6}$ James Q. Davies, 'Voice Belongs', in 'Colloquy: Why Voice Now', Journal of the American Musicological Society, 68/3 (2015), 677-81 at 680. Wayne Koestenbaum calls attention to some of the myths surrounding voice in similarly forceful terms; see, for instance, his remarks on voice culture's overvaluation of presence and the 'natural' in his The Queen's Throat: Opera, Homosexuality, and The Mystery of Desire (London, 1993), 155, 167 and 170.

7 The Era, 19 Nov. $1848,11$.

${ }^{8}$ Lind performed at Benjamin Lumley's Her Majesty's Theatre during the 1847-49 seasons, her most successful roles being those of Amina in La sonnambula, Maria in La figlia del reggimento and Adina in L'elisir d'amore.

${ }^{9}$ See The Times, 3 Nov. $1887,8$.

${ }^{10}$ The Magazine of Music, Dec. $1887,188$.

${ }^{11}$ Lind's retirement in 1849 seems to have been due mostly (though not only) to her religious beliefs; she nevertheless maintained a concert and oratorio career. On these topics, see Matildie Thom Wium, 'A Temperament of "Ideal Cast, Lofty Tone, Sacrificial Flame and Haughty Purity": Jenny Lind's Faith and Her Career' (forthcoming).
} 
'The one question of the day was, "Have you heard her?"' So recalled nostalgically the Magazine of Music, echoing pronouncements that The Era had made as far back as $1848 .^{12}$ This stance reflected a concern with direct access to Lind's voice: it granted an empowering force, even social and moral, to unmediated auditory experience. 'Nobody's information or education can be complete, or even liberal', had once assured The Era, 'unless he or she shall have witnessed the performances of the lady in question. ${ }^{13}$ This was no longer feasible in modern days. Voice - the carrier of presence, of identity, of personality-had been displaced by name-the leftover of the real, breathing self. A whole subjectivity had apparently been lost, and a void had emerged in its wake. 'To the majority of those interested in music of the present generation', said one critic for the Morning Post in a commemorative article, 'the name of Jenny Lind was a name and scarcely anything else. ${ }^{14}$ His tautology was intentional. He went on to retrace the main chapters of Lind's life and musical career, yet without dispelling the sense that, as a colleague of his had put it a few pages earlier, 'her final removal from the world' would at best not cancel her out as a 'memory' and as 'the ne plus ultra of sound and brilliant singing.' ${ }^{15}$ Some years later, the Musical Times articulated this voice/name binary with greater outspokenness. One of its critics lectured his readers:

The prima donna, fêted, idolised, and glorified in her lifetime, depends, nineteen times out of twenty, for her influence on the world at large upon such attributes as are annihilated when she reaches the term of her natural existence... . The prime donne['s] pleasant voices are all too soon swept by death the destroyer into the limbo of forgetfulness. . . . With the death of the last person who has heard the tones of her voice [the prima donna] becomes little more than a name.

Lind apparently made for an exception; her 'strong and interesting personality' granted her a more robust artistic and social influence, one that would linger on (this critic seemed to believe) even after her voice and ear-witnesses were hushed away by death. ${ }^{16}$ But the terms in which the dichotomy is explained are clear. Forsaking the various levels of mediationperceptual, cultural, technological - that produce a singer's voice, this critic endows an originary sonic object with an agency that operates as transparently as the related act of hearing. The very essence of the prima donna, we are told, lies with her voice: its sounding outwards and its resounding inwards, in listeners' minds. By contrast, name stands for a (faded) fame dissociated from the living individual-a Derridean index of absence, pastness and death. ${ }^{17}$

Those were, of course, newly phonographic times; ones, moreover, awash in end-ofthe-century nostalgia. At the risk of incurring technological determinism, one could take the Musical Times passage as symptomatic of burgeoning anxieties about rescuing vocal sounds from the doom of oblivion. As it happens, Lind's voice has come down to us only in the form (to borrow Mary Ann Smart's words) of 'ventriloquistic detritus': written accounts. ${ }^{18}$ From

\footnotetext{
${ }^{12}$ The Magazine of Music, Dec. 1887, 188.

${ }^{13}$ The Era, 19 Nov. 1848, 11.

${ }^{14}$ The Morning Post, 3 Nov. 1887, 5.

${ }^{15}$ The Morning Post, 3 Nov. 1887, 4.

${ }^{16}$ The Musical Times and Singing Class Circular, 1 July 1891, 393.

${ }^{17}$ See Jacques Derrida, The Ear of the Other: Otobiography, Transference, Translation, ed. Christie McDonald, trans. Peggy Kamuf (Lincoln and London, 1985). Distinctions between different types of fame have been subject to debate; for a useful account, albeit one at times overly schematic and reflecting mostly a twentiethand twenty-first-century perspective, see Chris Rojek, Celebrity (London, 2001).

${ }^{18}$ Mary Ann Smart, 'The Lost Voice of Rosine Stolz', Cambridge Opera Journal, 6/1 (1994), 31-50 at 32. Besides written descriptions, music has survived that was composed specifically for Lind. Meyerbeer wrote for her the
} 
the many contemporary sources, as partaking in mythologizing as they may be, we learn for example that the singer's intonation and capacity to pick up melodies were innate, almost absorbed from the 'harmony' of the Swedish countryside in which she grew up. ${ }^{19}$ Her flair for music and song revealed itself at an early age. At three, one early biographer assures us, 'singing was her ruling passion', an activity at which she would work away all the more eagerly in order to soothe the distresses caused by her sickly constitution. ${ }^{20}$ Anecdotes abound: as a three-year-old budding pianist, she would pick up military fanfares from outside the window and convert them for home use $;^{21}$ her mind would retain any melody that penetrated her ears, and her blue-ribboned cat would be enchanted by her singing. ${ }^{22}$ Yet for all that those early sounds deliver an image of Lind as endowed with an instinctive musicality, her vocal emissions, as she started to subject them to regular exercise, came across as spoilt with the dirt and worldliness exuded by hampered bodily organs.

That, at least, is one thread of the story (another is, admittedly, less daunted about fleshly constraints). In its natural, primitive state, Lind's voice seems to have had remarkable corporeal qualities. Before it was tamed by the singer's daily labour, it bore the marks of an imperfect physicality. The author of an 1860 collection of prima donna biographies explains how Lind had to work 'with indefatigable industry to remedy certain natural deficiencies'. Her voice 'was originally wanting in elasticity; she could neither hold her notes to any considerable extent, nor increase nor diminish their volume with sufficient effect; and she could scarcely utter the slightest cadence. ${ }^{23}$ Her organ, this writer continues, was 'neither naturally sweet nor powerful', and it took her time and moral stamina to carve out her widely praised vocal wonders of such 'bad materials'. ${ }^{24}$ Lind herself remembers these hurdles in a letter from 1868 :

the difficulties with my throat were so great, the hindrances were so tremendous, necessitating such constant energy and patience ... that only my burning love for Art in its spiritual sense could enable me to go through the dreadful slavery. My breathing was naturally very short, not a sign of coloratur [sic] and an impossible attack. ${ }^{25}$

Tellingly, some of the deficiencies detected in these accounts are the reverse of the qualities that came to be extolled the most in Lind's mature musical performances: extreme vocal flexibility, sustained breathing capacity, clarity of attack and so on. ${ }^{26}$ The gradual acquisition of vocal ease and control through practice was of course also a more general step in any singer's training. Lind was not alone in her vocal difficulties-Pasta, Malibran and other

\footnotetext{
part of Vielka in Ein Feldlager in Schlesien (1844), Verdi that of Amalia in I masnadieri (1847), and Balfe his scena ed aria 'Ah! Forse in tal momento' (1847).

${ }^{19}$ See, for instance, Henry Scott Holland and W. S. Rockstro, Memoir of Madame Jenny Lind-Goldschmidt: Her Early Art-Life and Dramatic Career, 1820-1851, 2 vols. (London, 1891), I, 13-14.

${ }^{20}$ See Anon., Memoir of Jenny Lind (London, 1847), 8, and Ellen Creathorne Clayton, Queens of Song: Being Memoirs of Some of the Most Celebrated Female Vocalists, 2 vols. (London, 1863), II, 330.

${ }^{21}$ See Holland and Rockstro, Memoir, I, 15-16.

${ }^{22}$ See Gladys Denny Shultz, Jenny Lind: The Swedish Nightingale (Philadelphia and New York, 1962), 27, and Holland and Rockstro, Memoir, I, 17 and 40.

${ }^{23}$ Clayton, Queens of Song, II, 335.

${ }^{24}$ Clayton, Queens of Song, II, 352.

${ }^{25}$ Lind to Professor [Oscar] Bystrom, 2 June 1868, repr. and trans. by V. M. Holmstrom in 'Jenny Lind's Singing Method', Musical Quarterly, 3/4 (1917), 548-51 at 550.

${ }^{26}$ For a detailed account of Lind's voice, see W. S. Rockstro, Jenny Lind: A Record and Analysis of the 'Method' of the Late Madame Jenny Lind-Goldschmidt (London, 1894).
} 
renowned singers had equally struggled to improve their faulty voices ${ }^{27}$-and accounts of her strains interweave with several other tropes that link her biography to a broader prima donna literature. Vocal crisis is another recurrent motive. ${ }^{28}$ Lind's was a voice twice lost and twice recovered. A capricious property at once cleaving to and relinquishing the body, it condemned the singer twice to that most tragic, most chronic form of a prima donna's loss. First, at twelve, her silvery tones and upper notes started to wear out, something that forced her to a bitter and premature first retirement. Four years later, a performance of Act 4 of Robert le diable in Stockholm, in which she took up last-minute the role of Alice, prompted a magical recovery. ${ }^{29} \mathrm{~A}$ second, more serious demise occurred at the age of twenty-one. It was due to over-exertion of her organs, and stamped her voice with 'chronic hoarseness and other marked symptoms of deterioration'. ${ }^{30}$ Although her voice's prelapsarian state eventually re-emerged following a period of training with Manuel Garcia jr in Paris, the repercussions were large, ingraining as they did many a trope of bodily impediments in press criticism. At as high a point in her career as 1848, Frazer's Magazine could be found deprecating the huskiness and fragility of her vocal constitution. ${ }^{31}$

To tune in to such critical accounts is, in one sense, less to excavate individual voices than to recover the values and anxieties that shaped them collectively (and no less importantly) at the level of discourse. As voices became biosocialised (as Foucault would have it) — categorised via gender, class, temperament, national origin and so forth - their individual contours became ever more blurred. What is more, and as Smart noted, the surviving evidence is often slippery because of the extent to which it is mired in comparisons and other contingent rhetorical gestures. ${ }^{32}$ The challenge all this poses to scholarly quests for the voices and musical personalities of past singers is inescapable, and facing it head-on in the future might itself contribute new directions to studies of voice. My aim here is less ambitious; it draws strength from a number of persistent tensions that ran through contemporary discourses about Lind's voice, tensions that can start deflecting us away from notions of voice as means or source of immediate self-expression, and encourage us to seek out Lind's sounds (also) elsewhere.

Some of the descriptions quoted above come with an invitation to auscultate the singer's body: to lend one's ear to new conceptions of vocality that, as Davies has retraced, were by around 1830 sinking the human voice ever deeper into the fleshly cavities of the self. While always connected to physicality, over the nineteenth century the voice became

\footnotetext{
${ }^{27}$ On Pasta see, for instance, Henry F. Chorley, Thirty Years' Musical Recollections, 2 vols. (London, 1862), I, 128-29.

${ }^{28}$ For a detailed overview of this literature, see Susan Rutherford, The Prima Donna and Opera, 1815-1930 (Cambridge, 2006). On tales of vocal crisis and their relation to identity formation, see Koestenbaum, The Queen's Throat, 126-29. For another leitmotif in nineteenth-century biographies of prima donnas, that concerning philanthropic activities, see Hilary Poriss, 'Prima Donnas and the Performance of Altruism', in Rachel Cowgill and Hilary Poriss (eds.), The Arts of the Prima Donna in the Long Nineteenth Century (Oxford, 2012), 42-6o.

${ }^{29}$ See for instance Clayton, Queens of Song, II, 332-4, and Anon., Memoir, 10-11. Lind's temporary loss of her voice's silvery tonal quality in her upper register may have been part of her natural growth process. Modern scientific research has identified huskiness and breathiness among the symptoms of female voice change during puberty; see Lynn Gackle, 'The Adolescent Female Voice: Characteristics of Change and Stages of Development', The Choral Journal, 31/8 (1991), 17-25.

${ }^{30}$ Rockstro, Jenny Lind: A Record, 6.

${ }^{31}$ See Frazer's Magazine for Town and Country, Mar. 1848, 339.

${ }^{32}$ See Mary Ann Smart, 'Verdi Sings Erminia Frezzolini', in Women and Music, 1 (1997), 33-45.
} 
increasingly welded to inner physiology and notions of individual expression. ${ }^{33}$ In Lind's case, those who belaboured the natural deficiencies of her organs were also performing another rhetorical move. One way of fathoming those body-centred nineteenth-century views is by seeing them as composing a politics of the voice geared towards emphasising Lind's moral virtues as well as her professional credentials. The greater the hindrances posed by inadequate lungs and wayward muscles, the greater the worth of Lind's Victorian stamina and of the newly-acknowledged professional status of female singers. ${ }^{34}$ Eventually she did manage (we are told) to master her ever-troublesome body. But what is most striking is that the mystic purity and steadiness of sound she was said to have achieved was only to complicate the status of her voice's relation to her body and her self. That her mature vocal performances are placed critically, and persistently, as much within as against the somatic regime just described is indeed significant in the context of the broader, changed pathology of the voice outlined by Davies.

One other leitmotif of historical descriptions of Lind's vocal utterances was their seeming disembodiment and immateriality: the impression they gave, particularly in widelyacclaimed coloratura passages, of proceeding from a source other than her body. The effect was uncanny - on occasion it was assimilated to 'a species of exquisite ventriloquism' - and found its most typical manifestation in Lind's celebrated 'Echo song' (a Norwegian folk tune, almost Lind's signature piece, in which she often accompanied herself at the piano). ${ }^{35} \mathrm{Her}$ voice, a soprano with a range encompassing between two octaves and two octaves and a sixth according to different accounts, ${ }^{36}$ was more generally described as characterized by purity, clarity and sweetness, qualities that hinted at a transcendence of the bodily domain even as they invited critics to scan their physiological origins minutely. Breathing is a good example. According to W. S. Rockstro, co-author of Lind's semi-official biography and of a detailed account of her singing method and cadenzas, her breath was 'wholly the effect of art'. Her sustained vocal power, her extraordinary capacity to swell and diminish the volume of long-held notes (especially $p p$ and in the high register) had nothing to do with physical disposition. While 'by the outside world [these powers were] attributed to abnormal capacity of the lungs', Rockstro explains, they stemmed from an unfaltering subjugation of bodily mechanisms which allowed her to refill her organs imperceptibly. ${ }^{37}$ The body as machine comes forth here in all its multiple components: the diaphragm, the lungs, the larynx, the epiglottis. And yet the anatomical labour disclosed in this process ultimately diverts voice into a sphere that comes close to the ethereal and the divine. 'Seraphic softness' was the trait one biographer identified in music that, almost by oxymoron, 'pealed through the house'; $3^{8}$ and another listener felt 'drowned' by the stream of sound,

\footnotetext{
33 See J. Q. Davies, “Veluti in Speculum”: The Twilight of the Castrato', Cambridge Opera Journal, 17/3 (2005), 271-301, and Davies, Romantic Anatomies of Performance (Berkeley, 2014).

${ }^{34}$ On the latter topic, see David Kennerley, 'Debating Female Musical Professionalism and Artistry in the British Press, c. 1820-1850', The Historical Journal, 58/4 (2015), 987-10o8, and Kennerley, “Flippant Dolls” and “Serious Artists”: Professional Female Singers in Britain, c. 1760-1850' (Ph.D. diss., University of Oxford, 2013). 35 The Morning Post, quoted in G. G. Foster (ed.), Memoir of Jenny Lind (New York, 1850), 38. For a longer account of Lind's 'ventriloquious' voice, see the excerpt from the New York Tribune quoted in Hollis Read, The Palace of the Great King (New York, 1859), 155-6.

${ }^{36}$ See respectively Chorley, Thirty Years'Musical Recollections, I, 305, and Holland and Rockstro, Memoir, II, 294.

${ }^{37}$ Rockstro, Jenny Lind, 9 and 15.

${ }^{38}$ Anon., A Review of the Performances of Mademoiselle Jenny Lind, during Her Engagement at Her Majesty's Theatre and Their Influence and Effect upon Our National Drama; with a Notice of Her Life (London, 1847), 19.
} 
'overwhelming as the Niagara', that poured out of Lind's 'mouth, without effort . . . as if a choir of seraphs were clustered within'. 39

Lind's sonic purity, supposedly a reflection of inner character, gets caught up in broader Victorian ideals of bourgeois femininity. It constitutes a symbolic space where vocal qualities, operatic roles and personality are conflated and negotiated with socio-cultural norms. ${ }^{40}$ Within a more firmly perceptual framework, though, the tension such purity creates with the biological body is one that re-emerges as another paradigm is introduced which dominated Lind's reception: the mechanical and the instrumental. Again, Davies has dug up important cultural precedents, showing how the vocality of late operatic castrati, in particular that of Giovanni Battista Velluti, was by the late 1820 s discussed in terms that reflected an increasing estrangement with the fetishism of technique typical of former decades. ${ }^{41}$ Sean M. Parr has also retraced how the coloratura of the mid-nineteenth-century soprano Caroline Carvahlo was aligned by French critics to the pyrotechnics of instrumental virtuosi. ${ }^{42}$ Lind was famous for her highly ornamental style, in many ways belonging to a past age. She typically excelled in bel canto roles, which she instilled with fully-fledged cadenzas and other embellishments. To some extent such flourishes evoked genius-like creativity on account of her 'unprecedented energy and boldness', her 'daring impetuosity', as one critic called them. ${ }^{43}$ Lind's presentations onstage appeared to merge aspects of creation and performance, and thus to reflect the growing endorsement of female genius and musical professionalism described by David Kennerley. ${ }^{44}$ And yet her glittering vocal displays also prompted fantasies of instrumentally- and mechanically-produced sounds. Her emissions' eerie qualities placed her body, perhaps to an even greater extent and in a more ghastly way than that of other contemporary singers, on the threshold of the human. The driving impulse was the 'sculptedness' of each of her notes. '[H]er voice resembled an instrument', declared the Morning Post in the aftermath of her London debut. 'Each note, as well as each word, is as distinct as a coup de marteau'. ${ }^{45}$ A couple of days later, the same newspaper likened the distinctness of her vocal emissions to 'the unerring quality of an harmonicon, or any other infallible instrument'. ${ }^{46}$ The piano lent itself to further comparisons. In one curious news item, which appeared in an Italian journal but reportedly derived from a French paper, Lind was compared to Liszt: her gullet (gorguzzule) was said to produce the same electrifying effects as each of the pianist's fingers. ${ }^{47}$ The pressures that Lind's voice exposed via these associations are revealed most obviously in two articles in which her singing both recalled and was set apart from the noise of machines. According to the Athenaeum, Lind's cadences in Roberto il diavolo 'less resemble the inventions of

\footnotetext{
${ }^{39}$ Anonymous letter in The Spectator, 14 Aug. 1847, 781. Commenting on one of Lind's celebrated diminuendos, a critic for the same paper also spoke of sounds that were 'as etherial [sic] as the sighing of a breeze [and yet] reached . . . every part of the immense theatre' (8 May 1847, 443).

${ }^{40}$ See Roberta Montemorra Marvin, 'Coming to Terms with Jenny Lind in Victorian England' (forthcoming; my thanks to the author for sharing an early version of her essay with me), and George Biddlecombe, 'The

Construction of a Cultural Icon: The Case of Jenny Lind', in Peter Horton and Bennett Zon (eds.), NineteenthCentury British Music Studies: Volume 3 (Aldershot, 2003), 45-61.

${ }^{41}$ See Davies, Romantic Anatomies, 31-8, and Davies, "Veluti in Speculum", 292-9.

${ }^{42}$ See Sean M. Parr, 'Caroline Carvahlo and Nineteenth-Century Coloratura', Cambridge Opera Journal, 23/1-2 (2012), 83-117.

${ }^{43}$ The Musical World, 15 May 1847, 320-1.

${ }^{44}$ See Kennerley, 'Debating Female Musical Professionalism' and “"Flippant Dolls”.

45 The Morning Post, 5 May 1847, 5.

${ }^{46}$ The Morning Post, 7 May 1847, 6.

47 Teatri, arti e letteratura, 12 Mar. 1846, 12. The critic for The Spectator compared the perfection 'in tone, tune, and articulation' of Lind's voice with that of 'a violin of a Paganini or a Sivori' (8 May 1847, 443).
} 
singing-master to be wrought out by singing-machine' ${ }^{48}$ Similarly, and again in a language that speaks of an acknowledgement of female genius, The Era assured its readers that 'Jenny Lind is not a mere singing woman-a vocal machine-but a serious artist'. ${ }^{49}$

Whether through bodily inspection or the reproductive codes derived from the mechanical and the instrumental, then, Lind's voice was vested in more than straightforwardly 'effluential' guises. Her sounds were blown up, dissected, analyzed; at once scanned for their ungraspable physical source and treated as if they possessed a substance of their own. This fetishism of the sonic object, which at times seems to turn human voice into inert, aseptic matter, destabilized its natural flowing out of Lind's body and soul. It is a fetishism that partakes of, but potentially also challenges, modern attitudes to voice. That we are so anxious to unpack what is distinct about and unique to individual voices-treating them as if they existed apart from their material and media surroundings-is telling of broader conceptions. As mentioned earlier, voice, particularly the singing voice, has a long history as a transparent signifier of subjectivity; as an empowering object that, particularly under the influence of literary and feminist studies, has been held to grant unmediated access to an originary individual presence. The voice's connection with the body has been paramount here, for precisely this connection-Barthes's famous 'grain'—charges vocal sounds with the capacity to index inner truths. This link and its accompanying pledge of authenticity have also played, jointly with the so-called performance turn in the humanities, into opera scholars' fascination with the idea of recovering 'lost' (mostly female) voices. Those phonographic anxieties about vanished voices and suspended selves are after all still with us, and they keep prodding us to quest for scattered traces of presence as we study past singing individuals.

Recent studies have nevertheless started to deconstruct vocal immediacy. Davies, for instance, has revealed a panoply of bodies and voices, as well as their mutual connections, none of which was natural or unmediated..$^{\circ}$ In a recent colloquy about the emergent field and stakes of voice studies, Brian Kane has similarly urged scholars to experiment with ways of addressing voice that do not steer us back into the pitfalls of a metaphysics of presence..$^{1}$ My question here is whether we could divert the voice even a step further away from its manifestation in (and of) the body and the self. My concern is with voice coming after techne, rather than before; more precisely, with an historical juncture-a sort of protophonographic moment-when reproduction technologies spawned a hankering after authenticity and presence. In this light, the Lind moment may be best understood as a paradigmatic episode in the emergence of modern conceits of 'pure voice'-an episode that is itself woven up into a broader historical trajectory. What if we pursued Lind's voice as inextricably bound up with material and media encounters? What if we listened to and through the celebrity craze ${ }^{52}$

\footnotetext{
${ }^{8}$ The Athenaeum, 8 May $1847,499$.

49 The Era, 11 June 1848, 11. Anxieties about automata and other dehumanized models of subjectivity, ones not infrequently associated with performers, were famously widespread during the nineteenth century; a particular inspiration for the singer-machine metaphor was E.T.A. Hoffman's short story 'The Sandman' (1816) and its singing protagonist Olimpia. Singing machines, however, were never perfected; see Carolyn Abbate, In Search of Opera (Princeton, 2001), Chapter 5.

$5^{\circ}$ See Davies, Romantic Anatomies.

${ }^{51}$ See Brian Kane, 'The Model Voice', in 'Colloquy: Why Voice Now', 671-7 at 672.

${ }^{52}$ Jonathan Sterne raises questions intersecting those under discussion in this article in his 'Afterword' to Karen Henson (ed.), Technology and the Diva: Sopranos, Opera, and Media from Romanticism to the Digital Age (Cambridge, 2016), 159-64 at 163-4, where he calls for an understanding of voice and opera as intrinsically and
} 


\section{Distributed voice}

I peered at her nit-pickingly, as they say, and so one needs to do with all celebrities. . ${ }^{53}$

Emanuele Muzio-Verdi's most famous, perhaps only, student-was adamant about what constituted de rigueur behaviour before celebrities: 'contemplating them thoroughly'. ${ }^{54}$ In an 1847 letter from London to Antonio Barezzi (Verdi's father-in-law and benefactor), he dwells on Lind's physical appearance. Her 'ugly face, serious, somewhat Nordic expression . . . and huge nose' offer an image of the soprano that thwarts physiognomic codes of intellect and inner beauty. ${ }^{55}$ Muzio's comments on Lind's countenance crop up in the midst of a broader examination of her musical qualities and personality. Bluntness aside, he was not alone in dissociating the visual semiotics from the gentleness and profundity he, as many others, discerned in her character. ${ }^{5}$ A large bulk of contemporary writers merged bodily grace with aural and attitudinal refinement, but others were less yielding-with Lind as with other opera stars-to idealistic fusions that masked what they considered the prima donna's lack of attractiveness. ${ }^{57}$

Muzio's urge to dissect Lind's physical appearance, though, is above all significant here because it underscores a drive to peer through the blanket of visual and other representations. Muzio's desire to fix the gaze upon the actual Jenny Lind epitomizes the discursive platform of Lind's celebrity. His comments resonate with the call for unmediated auditory experience mentioned earlier with regard to Lind's voice (remember The Era: 'It is actually necessary to hear Lind'). ${ }^{58}$ The face and the voice, the foremost loci of the self s authenticity in modern Western thought, bear all the allure of a supposedly pre-textual, 'anterior space'. ${ }^{59}$ In particular, and with regard to a more recent age, the voice's capacity to

deeply technological (that is, never unmediated, but rather shaped by physical environments as well as by the various forms of artifice that constitute human life).

53 'io l'ho voluta guardare bene per il sottile, come si dice, e così bisogna fare di tutte le celebrità': Emanuele Muzio to Antonio Barezzi, 29 June 1847, in Luigi Agostino Garibaldi (ed.), Giuseppe Verdi nelle lettere di Emanuele Muzio ad Antonio Barezzi (Milan, 1931), 334 (this and subsequent translations from Italian are my own).

54 'bisogna contemplarle bene': Muzio to Barezzi, 29 June 1847.

55 'La sua faccia è brutta, seria e vi è qualcosa di nordico . . . un naso grossissimo': Muzio to Barezzi, 29 June 1847 .

${ }^{56}$ Muzio describes Lind as 'buona, gentile e piena di educazione e di garbo . . . musicista perfetta e profonda' ('good, kind, graceful and well-mannered . . . a complete and profound musician'): to Barezzi, 29 June 1847.

${ }^{57}$ Roberta Montemorra Marvin discusses the crafting of prima donna images according to physiognomic codes of female virtue and respectability in her 'Idealizing the Prima Donna in Mid-Victorian London', in Cowgill and Poriss (eds.), The Arts of the Prima Donna, 21-41. In her essay 'Coming to Terms with Jenny Lind in Victorian England', she also quotes several contemporary accounts of Lind's physical appearance. Koestenbaum (The Queen's Throat, 104-105) underlines that physical flaws and even deformity are a leitmotif of biographies of prima donnas, for they signify difference and moral deviancy, qualities in which the magical powers of the divas' voices are rooted.

${ }^{58}$ Lind's face and voice on occasion directly evoked each other. In a poem inspired by an engraving of the singer, after carefully describing her countenance, the author Anna L. Snelling thus fantasized: 'In gazing thus we almost dream the while, / Those lips are parting with their wonted smile, / That heavenly voice in fancy we can hear': Snelling, 'On Seeing Mr Anthony's Portrait of Jenny Lind', New York Tribune, quoted from The Photographic Art-Journal, May 1851, 317.

${ }^{59}$ Laura Kunreuther, Voicing Subjects: Public Intimacy and Mediation in Kathmandu (Berkeley and Los Angeles, 2014), 19. On the face and the voice as traditional indexes of presence and immediacy, and for a challenging of such assumptions within a non-Western context, see in particular Chapter 2. 
unlock access to an originary presence has been connected to processes of mediatization. As Jonathan Sterne and others have proposed in their examination of developments associated with the emergence of sound recording technologies, the distribution of media versus sonic reality, copies versus originals, is one obvious repercussion of technological intervention. ${ }^{60}$ In an entirely different context, Richard Dyer has discussed the rhetoric of immediacy and authenticity concerning film stars and the media apparatus that frames them. Dyer perhaps gets closest to nuancing the dichotomy between reality and media when he points out that the hankering after the true self of the star is the result of a 'whole media construction ... that encourages us to think in terms of "really". It is the fragmentation and incoherence of a star's celebrity text that posit, beyond this reflecting, refracting surface, a unified, authentic individual. ${ }^{61}$

Even at the time, relatively few would have been in a position to gain direct access to Lind. That tireless chronicler of Victorian life and society, Punch, captured many a scene of exclusion. In a series of satirical sketches of so-called 'Jenny Lind nights', it drew attention to the saturation of human bodies that kept many would-be auditors far from the stage (Pll. 2 and 3). The view is from outside the auditorium: from the pit door; or from a recess communicating with the hall yet too removed not to be blind, and presumably deaf, to the operatic on-goings. People, seemingly aristocrats, proliferate along the imaginary trajectory that connects the exterior with the interior. They are caught as they attempt to burst in, or in despair at being forced to linger outside. The vanishing points of these pictures conjure up the anteriority of Lind's voice and figure. There is something loosely Foucauldian about these liminal theatrical spaces: about the tension between contiguous yet uneven spatial locations; about the distinctions articulated on thresholds that construct seeing-and hearing-as empowering mechanisms. These London snapshots contrast markedly (no doubt also owing to cultural stereotyping) with the overwhelming, formless gathering featured in another Punch vignette, one that depicts Lind's reception in America. Here the view is of a presence deceptively laid bare: Lind-marble-like, simulacrum-like-sits at the centre of a noisy scene that resounds only with the ragged voices of the crowd (Pl. 4).

\section{[INSERT PLL. 2, 3 AND 4 ABOUT HERE]}

The visual economy of these Punch sketches was corroborated by numerous written accounts. The 'ocean of humanity' and the 'multitudes [who] travelled from the most distant parts of the country' (William Gaspey's and George Hogarth's words respectively) provided subject matter for a close description by the critic for the Musical World, who reported on Lind's opening night at Her Majesty's. ${ }^{62}$ On his way to the theatre he would be 'impeded at every step by the crowds of idle gazers anxious to catch, if possible, a glimpse of the Swedish Nightingale'. The streets were 'gorged with vehicles, from the armorialised carriage of the aristocrat to the humble cab of the plebeian', and only those who succeeded in 'penetrating

\footnotetext{
${ }^{60}$ See Jonathan Sterne, The Audible Past: Cultural Origins of Sound Reproduction (Durham, NC, and London, 2003), esp. 217-21. The standard and related argument about liveness as an after-effect of mediatization is famously made by Philip Auslander in his Liveness: Performance in Mediatized Culture (London, 1999). See also Friedrich A. Kittler, Gramophone, Film, Typewriter, trans. Geoffrey Winthrop-Young and Michael Wutz

(Stanford, 1999).

${ }^{61}$ Richard Dyer, Heavenly Bodies: Film Stars and Society (London and New York, 2004), 2; see more generally 116. Rojek has also traced the emergence of the 'public face' alongside the notion of the 'veridical self' to the eighteenth century and in conjunction with a flourishing print culture; see Rojek, Celebrity, esp. 103-12.

${ }^{62}$ William Gaspey, Tallis's Illustrated London, 2 vols. (London and New York, 1851), II, 217, and George Hogarth, Memoirs of the Opera in Italy, France, Germany, and England, 2 vols. (London, 1851), II, 337.
} 
to the interior' would find recompense for their strains, from that moment on forming 'one living mass of souls', 'all bent upon one object'. ${ }^{63}$ In the aftermath of her death, one of Lind's many commemorators in the press recalled how 'her name was [once] cherished by hundreds of thousands of the poor and the working classes, in their humbles homes and in the London streets, though none of them could see or hear the famous songstress' ${ }^{64}$ Visual and verbal images construct a tension between presence and absence, between the evocation of an identity construed in strongly perceptual terms and a lack of phenomenological access to it. A paradox inherent in the mechanics of Lind's celebrity thus starts coming into focus: the singer's actual voice, as it was captured in the contemporary imagination, was in fact substantiated by the 'stuff' of Lind mania.

As described earlier, Lind was caught up in a thick media complex. From articles in the daily and musical press to the market of likenesses, musical scores and a startling variety of merchandise, greedy entrepreneurs hastened to supply pseudo-authentic Lind experiences. In commodified forms-published songs advertised as faithful records of performances, paintings and engravings, porcelain statuettes, and so forth-Lind penetrated everywhere. ${ }^{65}$ Indeed her spell on London society was often described by the press in epidemic terms, ones that tacitly assimilate the mobility or infiltration of sound to an altogether different, more material type of spread. In a two-instalment article entitled 'Jenny Lind and Her Influence', the critic for the Musical World delivered perhaps the most colourful account. He captured the dystopian excesses of the Lind craze, which he dubbed a 'melodious plague', a 'poison', an 'infection', a 'most delightful epidemic, that [hath] poured into the ear of old London such precious distillations as have ravished it beyond a cure!' ${ }^{66}$ Even before Lind's London debut, someone writing for another local paper fantasized about her arrival on the Thames, alerting his readers to a concurrence of mysterious sonic phenomena. As Lind rolled up to Blackwall by steamer,

The banker in his counting-house fancied for the instant that the chink of his sovereigns formed itself into a light melody; the merchant saw the words of the bills that came due arrange themselves into a musical staff decorated with various notes from the stately semibreve to the fluttering appoggiaturathe chimes of the Exchange clock were heard to give a fuller and more musical sound, and there was something orchestral in the rattle of the cabs and omnibuses. ${ }^{67}$

A chain of urban-noises-turned-musical evokes the spreading reach of Lind in auditory terms. Both these critics depicted Lind fever at a time when the soprano was at the height of her career; they thus offer a counter-image to the void bemoaned by those journalists facing her death. Yet they do so by homing in less on bodily vocal outpourings, more on what one might call the sonic properties of celebrity. To adopt in reverse the binary carved out by those later, end-of-the-century reporters, it was the prima donna's name-rather than her voice-that swept across the 1847 metropolis.

\footnotetext{
${ }^{63}$ The Musical World, 8 May 1847, 302-303.

${ }^{64}$ The Illustrated London News, 12 Nov. 1887, 561.

${ }^{65}$ George Biddlecombe discusses some of the visual aspects of the commercial craze in his 'Jenny Lind, Illustration, Song and the Relationship between Prima Donna and Public', in Christina Bashford and Roberta Montemorra Marvin (eds.), The Idea of Art Music in a Commercial World, 180o-1930 (Martlesham, 2016), 86-113 (my thanks to the author for sharing an early version of his essay with me).

${ }^{66}$ The Musical World, 29 May 1847, 341; the second instalment appeared on 12 June 1847. See also the Morning Post, 19 Apr. 1847, 5 ('a genius ... which had spread her fame all over the civilised world'), and C. L. Gruneisen, The Opera and the Press (London, 1849), 11 ('prima donna epidemic').

${ }^{67}$ The New Monthly Magazine and Humorist, May 1847, 117.
} 
Or, to be more precise, I would suggest that the two-name and voice-are mutually sounded and constituted. Here I am using 'name' in a somewhat different sense from that implied by those late-nineteenth-century critics: less as a detritus of a bygone individuality (a void pointing to an absence), and more as the accretion of texts and signs that go into an individual's celebrity. Scholars of celebrity studies have in recent years retraced the emergence of modern celebrity culture to around the late eighteenth century. ${ }^{68}$ Pursuing the visual and literary sides of these developments, they have suggested that a new cultural and industrial apparatus centred on print increasingly fostered the illusion of an unmediated contact between particular individuals and their audiences. ${ }^{69}$ English scholar Tom Mole has perhaps offered the subtlest account, exploring some of celebrity culture's 'hidden' mechanisms (for which he coined the notion of 'hermeneutic of intimacy' to explain a reading paradigm which is founded on acts of both revelation and concealment). Mole has highlighted that culture's 'tendency to conceal its own means of production': to produce the impression, in other words, that the fame of a star pours forth directly from their talentfrom their real, Ur-like self. ${ }^{70}$ This model, which maps out a putatively direct communication between celebrities and their audiences, has striking resonances with some classic loci of musicological interest. It can remind us, for instance, of once-traditional views according to which composers' and performers' genius would flow smoothly in and then out of their souls and bodies, translating into musical effusions binding them together with their audiences. While music scholars have both moved beyond this view and made their own significant contributions to the field,$^{71}$ celebrities studies has in some ways remained remarkably silent: it has for the most part eschewed the sonic implications of the cultural work and materials which celebrities perform and produce.

Name-celebrity_can be vocal, resonant, resounding; it can intertwine with a singer's voice in ways that both shape it and refract it. Lind's voice was immersed in and constituted by a dense materiality of things. Its perceptual and ideological connotations need to be situated within the fabric of Lind mania. We can best grasp echoes of Lind's vocal sounds if we listen through people, objects and discourses. For one thing, the aforementioned ubiquity that was associated with Lind's celebrity meant that her sounds were said to possess a penetrating, projectile power. The Morning Post noted how her 'every whisper ha[d] that penetrating quality that it reache[d] the remotest corners of a theatre'. ${ }^{2}$

\footnotetext{
${ }^{68}$ Until recently, celebrity has been regarded by scholars as a twentieth-century phenomenon. For an early, and widely-encompassing, historical overview of fame, see Leo Braudy, The Frenzy of Renown: Fame and Its History (Oxford and New York, 1986). For studies that have located an epistemic break during the late eighteenth to early nineteenth century, and for a helpful introduction to scholarly questions and problems in celebrity culture studies, see Mole, Byron's Romantic Celebrity: Industrial Culture and the Hermeneutic of Intimacy (Basingstoke and New York, 2007), Chapter 1. See also the essays in Mole (ed.), Romanticism and Celebrity Culture, 1750-1850 (Cambridge, 2009).

${ }^{69}$ This take reflects a shift from an interest in studying particular celebrity individuals to exploring the whole economic-cultural apparatus and mechanics of celebrity. P. David Marshall, for instance, has discussed the place of celebrity in the articulation of power; see Marshall, Celebrity and Power: Fame in Contemporary Culture (Minneapolis, 1997).

$7^{0}$ Tom Mole, 'Introduction', in Mole (ed.), Romanticism, 1-18 at 8; see also Mole, Byron's Romantic Celebrity.

${ }^{71}$ For three insightful studies of celebrity opera singers from a variety of perspectives, see Smart, 'The Lost Voice of Rosine Stolz'; Susan Rutherford, “La cantante delle passioni”: Giuditta Pasta and the Idea of Operatic Performance', Cambridge Opera Journal, 19/2 (2007), 107-38; and Karen Henson, Opera Acts: Singers and Performance in the Late Nineteenth Century (Cambridge, 2015).

${ }^{72}$ The Morning Post, 19 Apr. 1847, 5. See also The Illustrated London News, 8 May 1847, 301 ('To the fullest, purest, sweetest tone imaginable, it unites a vibrating and penetrating quality, that makes its softest whisper audible, no matter where the listener is seated'); Foster, Memoir, 57 ('Her voice in its sweetest tones penetrates
} 
The trope was often reiterated, and taps into a broader nineteenth-century ideology of 'vocal reinforcement' described by Steven Connor. This ideology emphasized the reach and puissance of the voice in contrast to earlier notions that praised sincerity, intimacy and distinctness. In Connor's account, the cultural configuration of the voice that became entrenched over the course of the nineteenth century was centred on masculine qualities such as strength and physical power. ${ }^{73}$ Lind's utterances nevertheless evoked an ambiguous mix of steadiness and fragility, of thrust and whispering lightness, thus pushing against any univocal trajectory. What they do is invite us to consider their placedness in-their mediatedness through-particular material and discursive locations. Their contours were shaped by opera houses in which, as the press never tired to report, 'a multitude, dense and compact' obstructed visual and aural access to the performer $;{ }^{74}$ or by the epidemic regime of spreading cultural reach that Lind's celebrity status entailed. The proliferation of bodies and signs demanded that her voice be heard and listened to across spatial and representational distance; even that it be endowed with a materiality and a reproductive quality of its own, relinquished from the limitations of its physical source. In an advertisement of a technology called the 'opera telakouphanon' (a 'speaking trumpet' for pitching voice across distance), Punch even predicted that Lind's 'liquid notes' would soon become a good for domestic fruition, one as easily supplied as water and gas to the homes of an increasingly networked metropolis. ${ }^{75}$

The material and semiotic concentrate of Lind mania, in which Lind's voice was moulded, is powerfully captured by a thought-provoking image: the cover of a midnineteenth-century London edition of the comic song 'The Jenny Lind Mania' (Pl. 5).

\section{[INSERT PL. 5 ABOUT HERE]}

This picture throws into relief some of the paradoxes of the mechanics of celebrity which I have been trying to tease out so far. Published by B. Williams, this sheet music encapsulates the furore triggered by Lind's London seasons. The song is credited to the comic singer W. $\mathrm{H}$. C. West. Its text is a humorous account of the Lind epidemic that took the local market by storm, while the music is an arrangement of the popular American blackface minstrelsy song 'Lucy Long' (which also provided the tune for a number of Jenny Lind ballads). ${ }^{76}$ The cover of this edition is worth pausing over. Its visual frame of reference attests to the frenetic industrial activity that characterized the Lind moment. It summons up-and bluntly so-the commodification processes that governed the cultural space occupied by the soprano. One of its most striking features is its self-referentiality: its musing on the media nature of the craze, of which West's song is part and parcel. The posters covering up the wall of 'Jenny Lind's emporium' constitute advertisements for a variety of merchandise marketed

\footnotetext{
the entire house-we hear as distinctly the long-sustained note of her first recitative when we enter the vestibule as we hear it in the pit'); and The Spectator, 8 May 1847, 443 (in fn. 39).

${ }^{73}$ See Steven Connor, Dumbstruck: A Cultural History of Ventriloquism (Oxford, 20oo), Chapter 15.

${ }^{74}$ The Era, 9 May $1847,10$.

${ }^{75}$ Punch, 15 (1848), 275.

76 'The Jenny Lind Mania: Comic Song Written and Sung by W. H. C. West' (London, n.d.). The song is n. 127 in Benjamin Williams' Cyclopedia of Music: Miscellaneous Series of Songs. Of William Henry Custance West, little is known. A portrait of him after a photograph is reproduced in Arthur Langley's song 'The Jolly Waggoner' (London, [1858]). The dates of composition and original publication of 'The Jenny Lind Mania' are uncertain. Some of Lind's biographers mention the song en passant in the context of the Lind craze in the US in the early 1850s; see Shultz, Jenny Lind, 230-1, and Isabelle Emerson, Five Centuries of Women Singers (Westport, CT, and London, 2005), 158-9 and 300 (fn. 27).
} 
under the aegis of Lind's name: cartes-de-visite, tooth powders, bonnets, oysters and the like. Their status as façade, as twice-removed tokens for the real Jenny Lind, is conveyed by the progressive layers in representation at which the picture hints. The warehouse cloaked behind the ads is the site where the material simulacra of the singer get manufactured; the posters then serve to catalyse and boost those items' exchange value. The commercial circuit could also be read the other way round, with the notices providing the premises for the artefactual ferment. But the cover's subject matter is nevertheless clear: less Lind, the woman and star performer, and more the cultural by-products and media buzz generated by (and generative of) her public persona.

The 'really' rhetoric (to echo Dyer) of historical discourses on Lind here seems at first glance altogether dismissed. ${ }^{77}$ The picture is at one level straightforwardly artificial: an architectural layering of signs in which the actual singer is at once invoked and concealed beneath the commodity gadgets and discourses she has generated. Only a few faint echoes of her human and aural presence are perceptible on closer inspection: in the top-left corner of the wall, where a playbill announces a performance at Her Majesty's Theatre; or in the bottom central advertisement, selling 'Swedish lozenges for the voice'. These are feeble traces nonetheless. It is the puzzle-like scaffolding functioning as a visual signifier of Lind mania that dominates vision. Most importantly, the ambiguous status of this sheet music, placed as it is both within and outside the referential realm it invokes, is substantiated by a further element of the cover: the title, which lies at the edge of signifier and signified. Placed, as it is, in a liminal typographical space that is unusual in sheet music covers from the period, its juxtaposition with 'Jenny Lind's emporium' means that 'The Jenny Lind Mania' is explicitly drawn into the composition of the image. Through this added arched top, which evokes the contours of town-house windows from the time, the picture gains even greater architectural concreteness —and, with it, a dot of representational immediacy. ${ }^{78}$

This cover subtly articulates the interplay of media and reality. It blends signifier and signified into a single, indissoluble unit, eroding the boundary between medium and object of representation. It also lends synthetic visual form to some of the strata of materials and discourses that constituted Lind. A concretion of objects and signs went into shaping the soprano's vocal and broader musical identity. To return to Kilburn's portrait (Pl. 1) for a moment, Lind's image, in many ways as blank as the two walls that surround it, only starts to gain semantic significance from the ambience of the room once this relatively underdetermined studio shot is embedded in a web of other texts - written, visual and aural ones. The room is bare, Lind is depicted neither 'at home' nor 'onstage', and her attitude is both contrived and difficult to decode. But her identity does take shape, when one acknowledges that broader context, from transactions that involve apparently perfunctory objects: a mirror that diverts the self out and back into 'itself'; a piano whose surfaces denote both musical creation and musical performance (thus retracing the twofold connotations that Lind projected onstage); a locale that both absorbs and magnifies the markers of Lind's singing persona. To attend to the meanings forged by these relations is to excavate Lind as a product of both material and media encounters. It also means listening to Lind's voice through physical and discursive environments, something that can help us to nuance the idea of the voice as an anterior and individual reality, and to relocate it after-rather than prior to-a

\footnotetext{
77 See Richard Dyer, Heavenly Bodies: Film Stars and Society (Basingstoke and London, 1986).

${ }^{78}$ Normally, if sheet music songs have an image on the title page, it is clearly distinct from and subordinated to the title. The layout of 'The Jenny Lind Mania', therefore, suggests that the publisher, who would have had control over the cover, is explicitly playing with the fact that the song itself participates in the commodity craze (my thanks to Oskar Cox Jensen for pointing this out to me).
} 
broader range of human and material activity. Auscultating more resolutely the stuff that proliferates around and about celebrity singers, that is, opens up space for a muddier vocal ontology: one concerned less with the values of presence and discrete individualities, more with a porous relational framework sustaining an identity politics where mediation is key.

\section{Serial real}

There is one final way in which the opposition between reality and media discussed in this article in relation to Lind's voice is further destabilized: through the proliferation of the serial sign. In his examination of the various 'orders of simulacra', Jean Baudrillard explains how in modern industrial (re)production societies seriality constitutes the real in a way different from that implied by the system of representation. Through mass-production of identical objects, the real ceases to be the foundation or objective space lying behind appearances in a specular regime (it is no longer even a lost original as with Benjamin's classic formulation). Rather, in the commodity economy, free-floating signifiers severed from all referents and pre-constituted truths self-generate reality through repetition, at the same time that they diffract the medium into such genetic acts. Hierarchical relationships of originals versus copies are suspended, exploded into a relational field of objects-signs defined by indifference and equivalence. ${ }^{79}$

Among the nineteenth-century forms that brought about this new, reproductive order of appearances, Jonathan Crary has noted, were photography and other techniques for the mass-production of images. ${ }^{80}$ One genre in particular almost self-reflexively-at a structural level—enacts the epistemic shift marked by seriality: the composite carte de visite. Cartes de visite were patented by André Adolphe Eugéne Disdéri in Paris in 1854, their introduction meaning that photography would become accessible to increasing sectors of society. Composite photographs first appeared in the $1860 \mathrm{os}$, and the most ambitious among them could assemble up to a thousand portraits. ${ }^{81}$ The subjects were popular icons, historical or of the day. The carte de visite reproduced in Pl. 6 was published by the Ashford Brothers firm in London in the mid 186os. Its subject-Operatic Prima Donnas-is squeezed into an extraordinarily small space (the longer side of the card measures less than $10 \mathrm{~cm}$ ). Twenty mini portraits, mostly (but not exclusively) photographic, are lined up in rows of four, each portrait enclosed in a white oval frame and dutifully carrying a name. The women captured in the collection were London operatic stars: from Marietta Piccolomini to Adelina Patti, from Pauline Viardot-García to Giulia Grisi and Lind. All of them, including a couple of intruders (a dramatic actress and a non-opera singer), were either active or had recently retired from the stage. ${ }^{82}$

\section{[INSERT PLL. 6 AND 7 ABOUT HERE]}

\footnotetext{
${ }^{79}$ See Jean Baudrillard, Simulations, trans. Paul Foss, Paul Patton and Philip Beitchman (New York, 1983).

${ }^{80}$ See Jonathan Crary, Techniques of the Observer: On Vision and Modernity in the Nineteenth Century (Cambridge, MA, and London, 1990), 13.

${ }^{81}$ See Robin and Carol Wichard, Victorian Cartes-de-Visite (Princes Risborough, 1999), 42-3. For a detailed account of the history of the carte de visite in France, see Elizabeth Anne McCauley, A. A. E. Disdéri and the Carte de Visite Portrait Photograph (New Haven and London, 1985). For their functions and consumption, see John Plunkett, 'Celebrity and Community: The Poetics of the Carte-de-visite', Journal of Victorian Culture, 8/1 (2003), 55-79.

${ }^{82}$ From the top left corner: Guerabella [Genevieve Ward], Catherine Hayes, Euphrosyne Parepa-Rosa, Elizabeth Poole, Adelaide Borghi-Mamo, Marietta Piccolomini, Adelina Patti, Eugénie Doche (actress), Pauline Viardot-García, Jenny Lind, Giulia Grisi, Louisa Pyne, Constance Nantier-Didiée, Marietta Alboni, Therese Titiens, Clara Novello, Erminia Rudersdorff, Charlotte Sainton-Dolby (concert, ballad and oratorio singer), Marie Caroline Miolan-Carvalho and Rebecca Isaacs.
} 
This compilation of prima donnas invites exegesis at different levels. The tags attached to the portraits point to an exuberance of meanings: the names identify the women in question, but they also suggest that each of them had accrued a significance that reached beyond the semantic potential of a single snapshot. The visite also underscores a cumulative narrative arc. The assemblage was produced at a time when, as Rachel Cowgill and Hilary Poriss have explained, the very 'idea of imagining a group history' for professional female opera singers was taking shape. ${ }^{83}$ Not least through its visual codes, the collection marks an attempt to canonize these women, in so doing policing both the by-products of a burgeoning celebrity culture and the plethora of discourses (about moral, social and cultural threats) in which prima donnas had long been embedded.

The picture also challenges any straightforward relationship between representation and reality. The women captured in this roster are branded within an unchanging visual language. Ovals, stars and linear arrangements create an orderly geometric pattern that subsumes diverse female individualities into mechanical, repetitive gestures. A rising commodity culture is evoked which explodes identities into myriad all-too-replaceable signs. This dispersion of the signified-subject into a swarm of doubles is taken further by another Ashford Brothers visite (Pl. 7). This second photograph assembles five hundred portraits of famous people, each one now dislodged of any demarcating shape and nested into a kaleidoscopic crowd of miniaturized human beings. Lind, who features in the same portrait (again by Kilburn) used for the card in Pl. 6, appears about one-fourth from the bottom, just right of the central axis. There is an order, too, in this composition, particularly near the margins and through the loosely concentric arrangement of the figures (with smaller groups inscribing further regularity into the pattern). But the configuration is overall less rigid, and its multiplicatory logic enacts visually the mass-(re)production regime. That this visite (as the earlier one) was meant for close inspection with the help of a handmagnifying glass' was typical of the genre, as was its promise of authenticity, implicated by the publishers' claim that 'every portrait will be seen perfect.' On another level, though, the card blows up all referential obligations. Its outer unreadability makes the problem of identity one that is less about the correspondence of signs to objects, and more about the extraction of any discriminating principle from the flattening gesture of seriality.

The modern self's strained unity and individuality were variously articulated, as I mentioned early on in this essay, by photography. The mirror featured in Kilburn's daguerreotype, as well as in other contemporary examples, was one accoutrement that exposed the fragmentation of subjectivity. ${ }^{84}$ Multiple shots of the same sitter in a series could also produce similar effects. As one early commentator remarked about a series of photographs of Lind taken by Mathew Brady in New York, 'There were eight likenesses taken in all, and every one differed from the rest, so changeable is the expression of the countenance of the great cantatrice. ${ }^{85}$ With the Ashford Brothers' cartes de visite, the presence and immediacy enfolded in each individual representation are questioned-in a Baudrillardian sense, even revoked - by the juxtaposition of almost identical signs. Perhaps this is why names are introduced in the Operatic Prima Donnas card. The tags re-inscribe an indexicality, a tension towards originals, which the serial economy has written off.

\footnotetext{
${ }^{83}$ See Cowgill and Poriss, 'Introduction', in Cowgill and Poriss (eds.), The Arts of the Prima Donna, xxvii-ilvi: xxviii. Cowgill and Poriss suggest that Ellen Clayton's Queens of Song is an early example of this trend.

${ }^{84}$ See von Brevern, 'Resemblance after Photography', 4-6 and 16-18.

${ }^{85}$ Quoted from The Musical World, 19 Oct. 1850, 671.
} 
But to stay with the implications of seriality: that might also be a direction worth pursuing in singer and voice studies in the future. If a certain type of real and identityformation may that way remain concealed, pausing over the endlessly repetitive gesture might allow others to come to the fore. Where one cannot retrace singers' voices as unique, distinct entities - for much surviving nineteenth-century evidence, as we know, rather pulls into the opposite direction - it might be possible and indeed productive to think them out via alternative categories: those of technique, or craft, or reproduction. The move is similar to the one required by investment in vocal sounds as mediated, in that it means reinscribing voice and the self in a texture of relationships that both enable and challenge the very idea of a self-standing individual voice. Rather than mourn, or sustain the mythos of, Lind's and other lost voices, we may occasionally rejoice in celebrating the manifold encounters that are always embedded in any voice. The Ashford Brothers' cartes de visite might not im-mediately capture Lind's sounds; the cards' ornamental motifs are perhaps the only echoes of the boundless musical decorations the soprano used to infuse into her singing. But the lack of a definitive sonic haven as the outcome of the historical endeavour is also the space where other voices and stories can come to emerge. To return one final time to those emotional, post-mortem commentaries on Lind's vanishing influence, Henry S. Holland sheds a more consoling light on the handover between voice and name:

Why is it that the name of Jenny Lind has become a household word in England, familiar to thousands who never heard her sing a note, or saw her face, but who, somehow, associate the sound of her name with everything that is most kindly, and pure, and tender, and good, so that they feel a sort of affection for one who, though unknown to them, about whom they could only tell you that she was a successful singer, has yet left a fragrance about her memory, which makes her name sound sweet and dear, as the name of a friend? ${ }^{86}$

Presence and absence are equally prominent and interconnected here. In fact the tension between the two seems all but to inflate whichever end of the continuum one seeks out the most. 'Jenny Lind' - a sound intrinsically sweet and musical in English-was at one point severed from a particular type of human presence; and yet it remains, in Holland's testimony, as replete as it could ever be with the sundry meanings it has, in time, accumulated. If this is voice, it is one of an abiding sort. If name can sing, it does so more vastly and more communally than individual life is able to encompass. As Lind faded into inaudibility, 'Lind' got a chance to project its multifarious voices out loud.

\footnotetext{
${ }^{86}$ Henry Scott Holland, 'Jenny Lind', Murray's Magazine, Dec. 1887, 721-31 at 721.
} 